\title{
Micro-Hydro Power Plants (MHPP): Technical and analytical studies in creating experimental learning media for physics students
}

\author{
Zuffa Anisa 1, a *, Anggun Apprianda 1, b, Herta Novianto 1, c, Indriyani Rachman 2, d \\ 1 Universitas Bojonegoro. Jl. Lettu Suyitno No 2 Bojonegoro 62119, Indonesia. \\ ${ }^{2}$ The University of Kitakyushu. 4-2-1 Kitagata, Kokuraminami-ku, Kitakyushu-shi, Fukuoka, Japan \\ a zuffa.anisa@gmail.com, b anggunafrianda9@gmail.com, ${ }^{c}$ hertavia@gmail.com, \\ d rachmanindriyani@gmail.com \\ * Corresponding Author.
}

Received: 25 September 2020; Revised: 22 December 2020; Accepted: 28 January 2021

\begin{abstract}
Nowadays, direct media use in learning energy is rarely found. Therefore, the authors intended to design a mini micro-hydro power plant (MHPP) in order to give direct experiences to students. This study generally aims to develop a mini MHPP consisting of equipment design, component selection, and the MHPP assembly. A test on discharge, heights, and produced power is then conducted. The data acquired are then analyzed in terms of either Pteotirik or Preal power using a predetermined equation. An analysis to the factors influencing the $P$ values is then carried out. The power input of $P$ _in resulted from the water discharge management is $35.64 \mathrm{~mW}$, while that of the power output P_out is $9,61 \mathrm{~mW}$. The efficiency of the MHPP set is by $26.96 \%$ which is considered quite low due to such factors as turbine blades, penstock pipes, generators, and the shift from water potential energy to other types of energies which is inevitable. It is expected that the developed mini MHPP is applicable as practicum learning media giving a lot of such learning experiences to students as to identify how hydroelectric power plant is, how the water energy shifts into electric energy, how high the electricity produced is, and to analyze factors influencing how high and low the electricity produced by a power plant. Keywords: MHPP; Turbine; Generator; Micro-Hydro; Energy
\end{abstract}

How to Cite: Anisa, Z., Apprianda, A., Novianto, H., \& Rachman, I. (2021). Micro-Hydro Power Plants (MHPP): Technical and Analytical Studies in Creating Experimental Learning Media for Physics Students. Momentum: Physics Education Journal, 5(1), 53-64. https://doi.org/10.21067/mpej.v5i1.4876

\section{Introduction}

Electricity consumption from renewable energy sources seems to be very poor. More than 80 percent of the power plant's electricity supply comes from fossil fuels. There is only a very limited number of power plants whose source is water energy, which is less than 10 percent (Goyena, 2019; Triboesono, 2018). In fact, as a source of electrical energy, the presence of fossil fuels is declining, they are not environmentally friendly, and they cannot be renewed. Increasing the number of power plants whose energy sources can be renewed, such as water, biomass and the sun, is one way to reduce the dependency of power plants on fossil fuels. Hydropower is one example of a renewable energy source.

Hydropower seems to be a very inexpensive and efficient renewable energy source (Erinofiardi et al., 2017). Furthermore, due to the presence of water supplies, both from small and large rivers, the production of hydropower in Indonesia has considerable potential. A micro hydro power plant (micro hydro power plant/MHP) might harness all of this. Furthermore, micro hydropower plants are an environmentally sustainable source of energy, low operating costs, long plant life and a renewable source of energy for water (Bhatia, 2014). 
According to Indonesian energy statistics, coal and natural gas are still the source of electrical energy supply, which is 83 percent, while the availability of electrical energy from hydro power is still 5 percent (Syahrial et al., 2011). In fact, the potential for power plants that can be built from hydropower sources is very substantial (Nasir, 2014). Most of the water supplies are actually still used only for irrigation, maize grinding, and ancient mining. The younger generation, therefore, who are ready to think critically and contribute positively to the exploitation of potential energy sources from micro hydropower, must be prepared.

Each university needs to prepare their students both for a good understanding of current energy issues and for technical training in the planning of a micro-hydropower plant as a source of new and renewable energy needs. For this reason, in the midst of the supply of electrical energy sources from fossil fuels whose presence is increasingly depleted and requires special attention, in particular energy is an important aspect to research, such as electrical energy, mechanical energy, it is necessary to prepare real learning media about this issue (energy). Potential and energy from kinetics).

A mini micro hydro power plant has not been used by many universities as a realistic learning medium at present. The purpose of this research is to design a practical instrument in the form of a miniature micro hydro power plant. It is expected that students could obtain direct experience of new energy and technology by developing this practice-based learning platform. Students could understand the factors that influence the amount of energy generated from an environmentally friendly generator technically and profoundly, and therefore can later solve problems in its application to industry and the workplace. The authors performed a scientific and theoretical analysis on the manufacture of a micro hydro power plant in order to use this generator instrument as a platform in practical learning.

The basic principles that need to be studied in the production of hydroelectric power plants include: the definition of a power plant, the classification of power plants on the basis of the amount of power produced, the efficiency of the power plant and the important components of a hydroelectric power plant, including dams, turbines and generators.

Micro Hydro Power Plants or what is meant by Micro Hydro Power Plants (PLTMH) are smallscale power plants that use hydropower as their driving force, such as irrigation canals, rivers or natural waterfalls, using head height and water discharge.

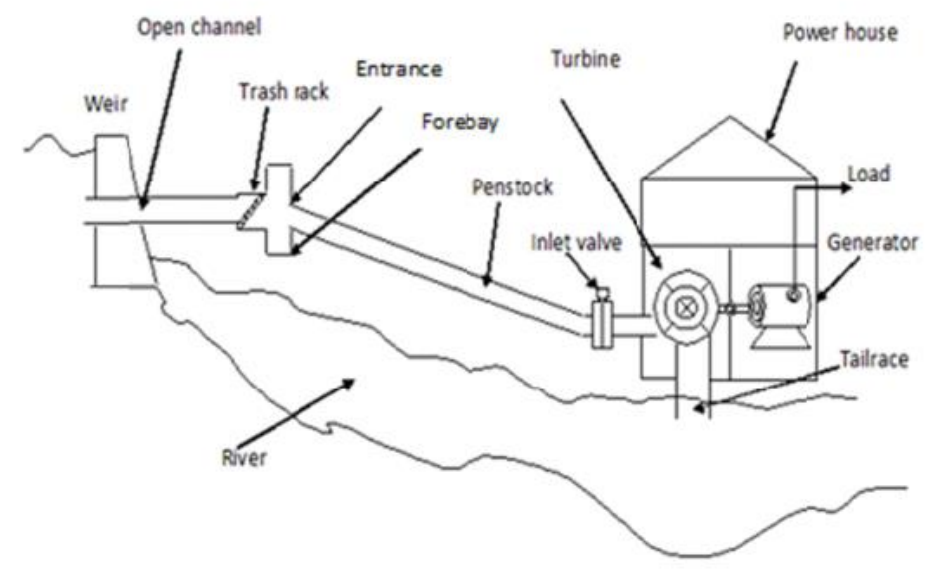

Figure 1. Schematic of Micro Hydro Power Plant

In Figure 1, the configuration of the micro hydroelectric power plant (MHP) is shown. In designing a micro hydro power plant, there are many items to consider, such as field topographical surveys, calculation of water levels and discharge, components of construction work (dams, spillways, intakes, channels, Penstock), turbine type range, and specifications of the generator (Nasir, 2014; Sungai et al., 2008).

Based on the amount of electrical power produced, Micro Hydro Power Plants (MHP) can be classified in Table 1 (Hatata et al., 2019). 
Momentum: Physics Education Journal, 5 (1), 2021, 55

Zuffa Anisa et al

Table 1. Hydro Power Classification

\begin{tabular}{cc}
\hline Hydro Type & Scale \\
\hline Large Hydro & More than $100 \mathrm{MW}$ \\
Medium Hydro & $15-100 \mathrm{MW}$ \\
Small Hydro & $1-15 \mathrm{MW}$ \\
Mini Hydro & $100 \mathrm{~kW}-1 \mathrm{MW}$ \\
Micro Hydro & $5-100 \mathrm{~kW}$ \\
Pico Hydro & $100 \mathrm{~W}-5 \mathrm{KW}$ \\
\hline
\end{tabular}

Penstock pipes, dams, turbines, and generators are the primary components that influence the MHP. Several elements and their respective functions will be presented below.

Penstock pipes and dams: As water flows through the penstock pipes, slowly converting into pressure energy, the potential energy decreases. The efficiency of this shift in energy depends on the friction (length and roughness of the inner pipe wall), pipe loss and carnene intake L (Tapia et al., 2018). Thus, the $\mathrm{Hg}$ between the dam and the power house minimizes the loss of energy by minimizing the penstock pipe length and the number of $L$ bows.

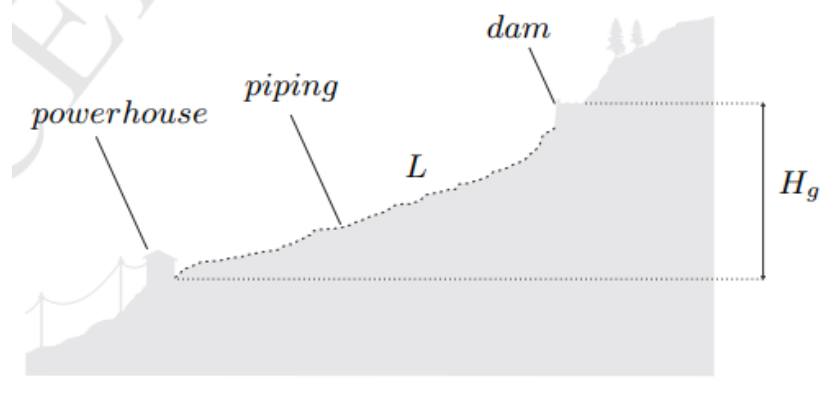

Figure 2. River Profile Scheme

The components for developing MHPP (Micro Hydro Power Plant) are presented in Figure 2. Potential energy is transformed into kinetic energy in the penstock pipe, while energy is converted from mechanical energy (kinetic and potential) to electrical energy in a power house (Signe et al., 2019). In order to provide a smooth flow of water into the penstock pipe, small dams are normally built as then friction and air entry do not occur [8] (Tapia et al., 2018).

The height (head) and water discharge are the variables that affect the amount of power produced from a MHPP generator (Q). The following equation can be used to formulate the sum of potential electric power produced from a micro hydro power plant (Bhatia, 2014)(Kumar \& Singal, 2015; Lahimer et al., 2012; Michael \& Jawahar, 2017).

$P=\eta \rho Q g h$

Where

P: Power (W)

$\eta$ : the overall efficiency of the turbine, generator, and gearbox

$\rho$ : density of water $\left(\mathrm{kg} / \mathrm{m}^{3}\right)$

$\mathrm{Q}$ : water discharge $\left(\mathrm{m}^{3} / \mathrm{s}\right)$

$\mathrm{g}$ : acceleration due to gravity $\left(\mathrm{m} / \mathrm{s}^{2}\right)$

h: below the free surface $(\mathrm{m})$

It can be seen in this equation that the power generated from the dam depends on $\mathrm{h}$ and $\mathrm{Q}$. This means that with a large discharge $Q$, a high dam with a small discharge $Q$ will generate the same power as a low dam. In addition, the efficiency of all generating components is also affected by the amount of electrical energy generated (Safdar et al., 2020).

In a hydropower plant, there are different turbine types used. The shape and form of turbine is modified to the conditions of developments in water level, volume and technology. Turbines were initially used to flow water underneath the undershot waterwheels (Figure 3a). Then it develops into the overshot waterwheels in Figure $3 b$, the blade form is further enhanced for flows above or beyond the turbine to produce a better kinetic energy flow (Figure 3b). 


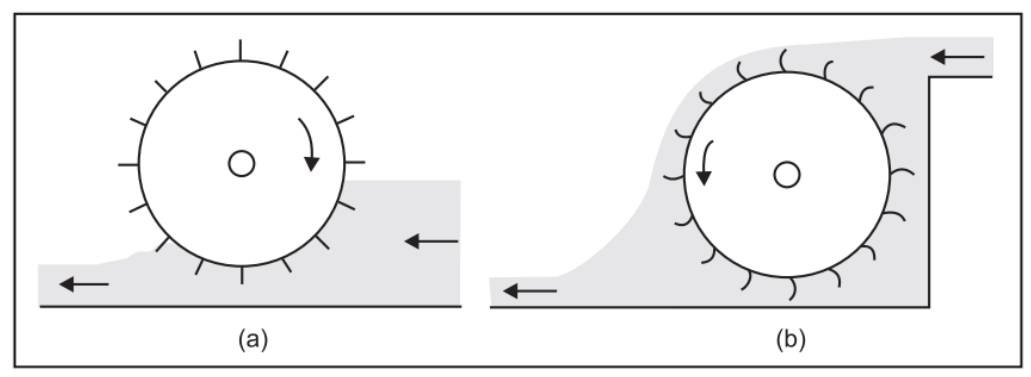

Figure 3. (a) Undershot and (b) Overshot waterwheels

Depending on the needs and to maximize the efficiency of the kinetic energy that is obtained, the form of the turbine is becoming increasingly diverse. The shape of the turbine is modified on the basis of the water height and flow produced by the micro hydro source. Choice of turbine in terms of head $h$ and volume flow rate $Q$ in figure 4 .

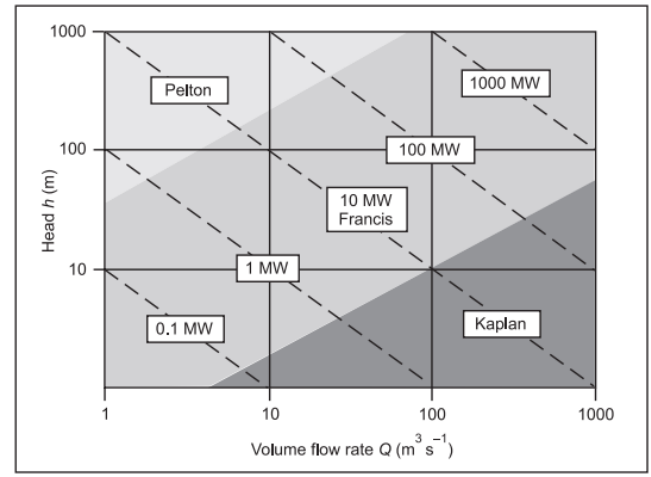

Figure 4. Choice of turbine in terms of head $h$ and volume flow rate $Q$

Turbine selection depends on the conditions in the region, including the level of water and the discharge of water. The form of the Pelton turbine in Figure $5 b$ ) is the most suitable shape for different forms of height and discharge of water, such as rapid mountain water flow. For tiny heads and wide water flows, Kaplan style turbines are suitable. Francis turbines, meanwhile, are mainly used for broad discharges and heads (Bhatia, 2014). The turbine and the nozzle pipe output can be seen in real terms in Figures 5, 6, and 7 (Kumar \& Singal, 2015).
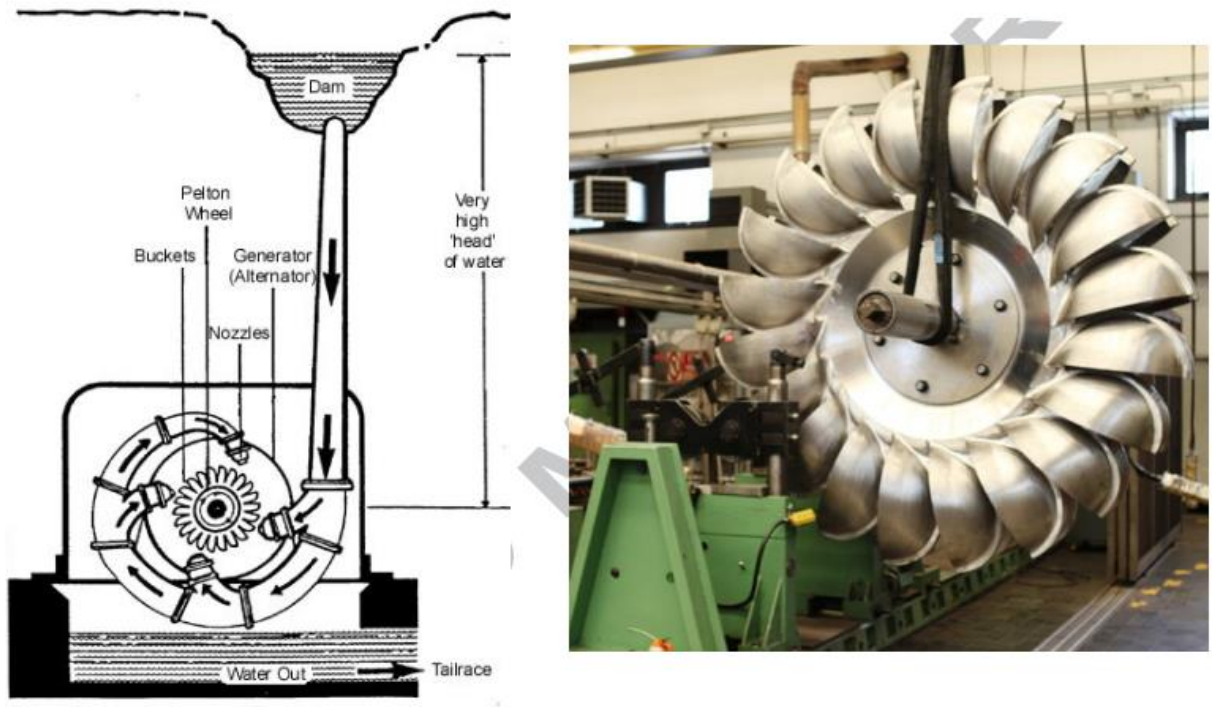

Figure 5. a. Scheme of pelton hydropower stations, b. Pelton turbine 


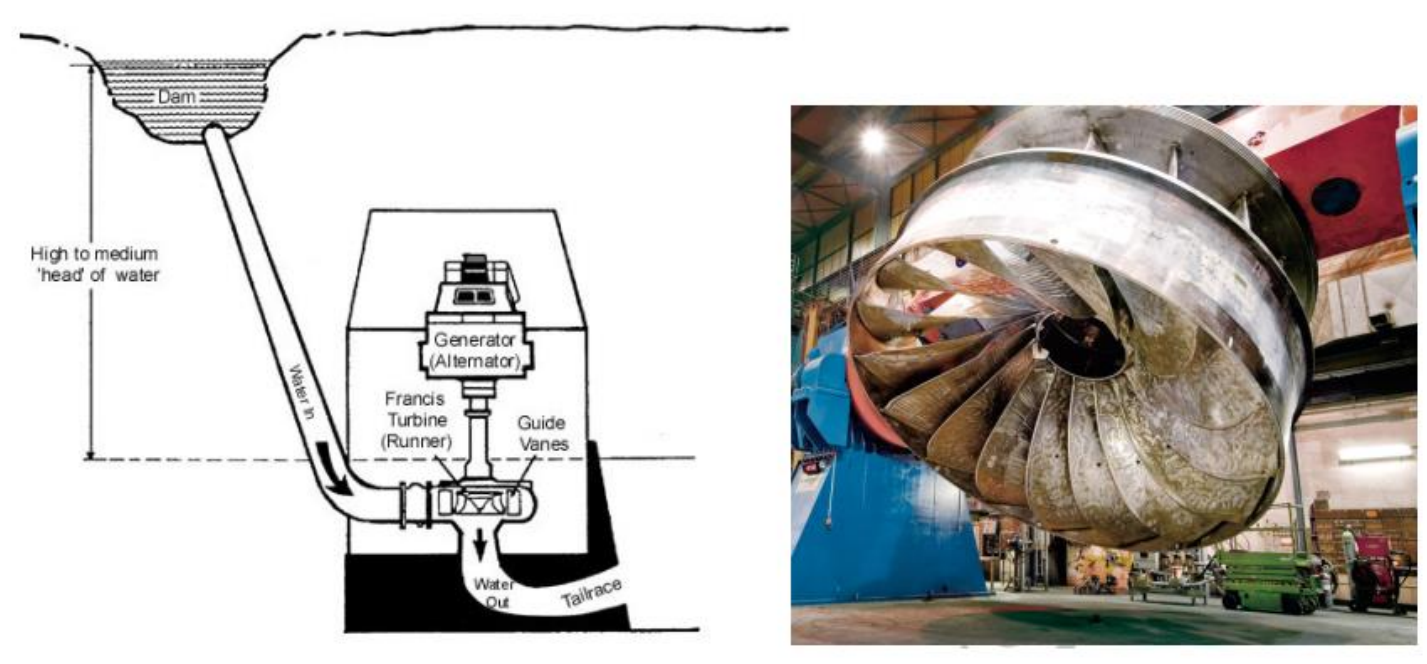

Figure 6. a. Scheme of francis hydropower stations, b. Francis turbine
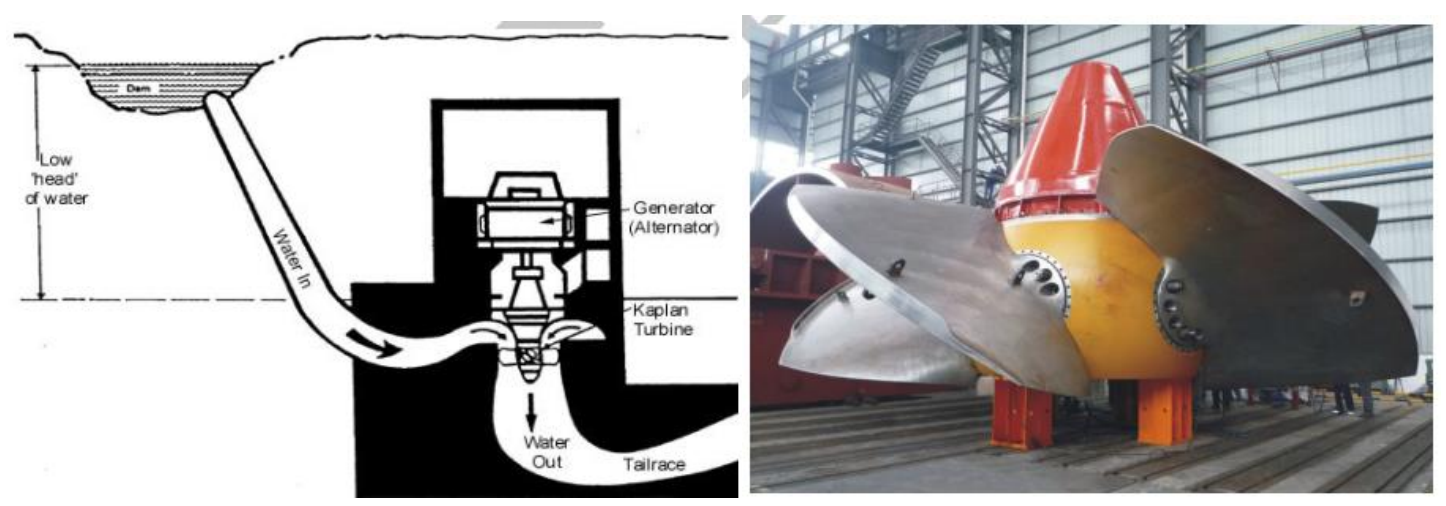

Figure 7. a. Scheme of Kaplan hydropower stations, b. Kaplan turbine

Water comes out of the pipe at the end of the penstock pipe (Figure 8) into the nozzle to turn the water pressure into kinetic energy at home. Pelton's turbine blade is struck by this water pressure, making it spin. The efficiency of this transformation of energy depends on the rotor's nozzle, shape and material. Before the mechanical energy of the rotor is eventually transformed into electrical energy by the generator, with the efficiency of the generator itself.

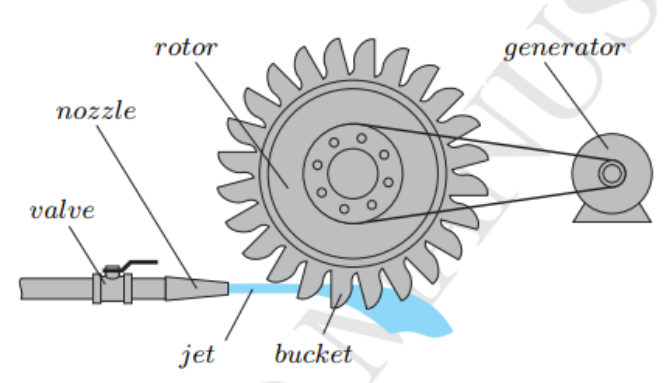

Figure 8. Pelton turbine working scheme

The generator is a system that converts electricity from mechanical energy. The generator operates on the basis of the electromagnetic induction theory, which is by turning a coil in a magnetic field to generate an induced emf. There are two primary components in the generator, including the stationary part (stator) and the moving part (rotor). The rotor is connected at the center of the stator to the generator shaft that rotates. Using external effort that may come from the engine, both water turbines and other turbines, the generator shaft is normally rotated.

There are two types of generators: synchronous generators and asynchronous generators (induction generators). The standard used in power generation is synchronous generators and they 
are used in most power plants. In order to generate constant power at a frequency of $50 \mathrm{~Hz}$, all generators must be powered by constant rotation. A four-poles generator with a rotation of about $1500 \mathrm{rpm}$ is commonly used for micro hydro.

\section{Method}

The manufacture of micro-hydro-power plants as an instrument for electrical energy and power in the practice of basic physics learning was carried out in phases such as preliminary theoretical assessment and study, the design of instruments and the selection of equipment, the selection and manufacture of innovative turbines, the selection and development of other components of MHPP, generator form and power selection, turbine instrument assembly, other parts and generators into one. Then, when the maximum power was attained, the test was carried out, then the MHPP setting was finished.

Theoretical evaluation and preliminary study of micro-hydro-influencing technological factors, including the evaluation of generator models, other MHPP parts, and turbine types were carried out. The MHPP system design was decided after the theoretical analysis was completed. Selection of instruments and materials to be used in the construction of turbines and generators, as well as other MHPP equipment parts were then performed. Creative turbine manufacturing was also done by selecting the type, volume and material of the turbine Pelton blades to be used. Then, it continued with shaft selection between the turbine and the generator, powerhouse manufacturing, belt selection that connects the turbine to the generator shaft. Generator selection was done by selecting the type of generator, generator capacity, and selecting the optimum generator shaft rotation.

The components were assembled into one after all the key components have been developed. The instrument was checked multiple times after assembling it correctly. The tests performed include the resulting tests for current and voltage, the measurement of the electrical power produced from this mini-power plant, and the discharge and height tests to compare the theoretical power potential to measure the efficiency of a generator. Then, variations of the head and water discharge test to assess the wide variance in generated electric power were determined. After the variations were carried out, an analysis was performed where it is possible to achieve the maximum electric power and the factors that affect it. An analysis and correction were then performed to achieve the optimum and best MHPP collection. The phases of this analysis as a whole can be seen in Figure 9 .

This study was carried out at the Faculty of Science and Engineering of the University of Bojonegoro. The development and testing of the instruments was carried out between March and July 2020. The instruments and materials used in this study were multitester, flowmeter, drill, glue gun, saw, wooden board, acrylic glass, penstock pipe, hose, water dam, water pump, creative turbine raft materials, connector cables and crocodile clamps, shaft materials for turbine turbines, creative materials for turbine blades, small dams and supports, valves, solutions, drawing paper, compasses, generators, clamps, nuts, bolts, LED lights and house miniature to complete the powerhouse.

The data collection method and data analysis were categorized into three parts as follows: Calculation of the potential for electric power $\mathrm{P}_{\text {theoretical }}$ Real power measurement $\left(\mathrm{P}_{\text {real }}\right)$ generated from $\mathrm{MPHH}$, and analysis of factors that affect the amount of power generated from MPHH.

\section{Calculation of the potential for electric power $\mathrm{P}_{\text {theoretical }}$}

The amount of potential power generated can be known by the equation measuring the height (Head) and discharge (Q) of water coming out of the nozzle valve penstock (Lahimer et al., 2012).

$P_{\text {theoretical }}=\rho Q g h$

Real power measurement $\left(\mathrm{P}_{\text {real }}\right)$ generated from MPHH

The real electric power generated from a generator can be determined by reading the current or voltage generated from the multitester and then calculated by the Formula 3. 
Momentum: Physics Education Journal, 5 (1), 2021, 59

Zuffa Anisa et al

$P_{\text {real }}=I^{2} R$ or $P_{\text {real }}=V I$

Analysis of factors that affect the amount of power generated from MPHH

Analysis of the overall total efficiency of the mini MHPP set that has been constructed based on the power results obtained from the two points above (Bortoni et al., 2015) were using the Formula 4.

$\eta=\frac{P_{\text {real }}}{P_{\text {teoritik }}}$

4)

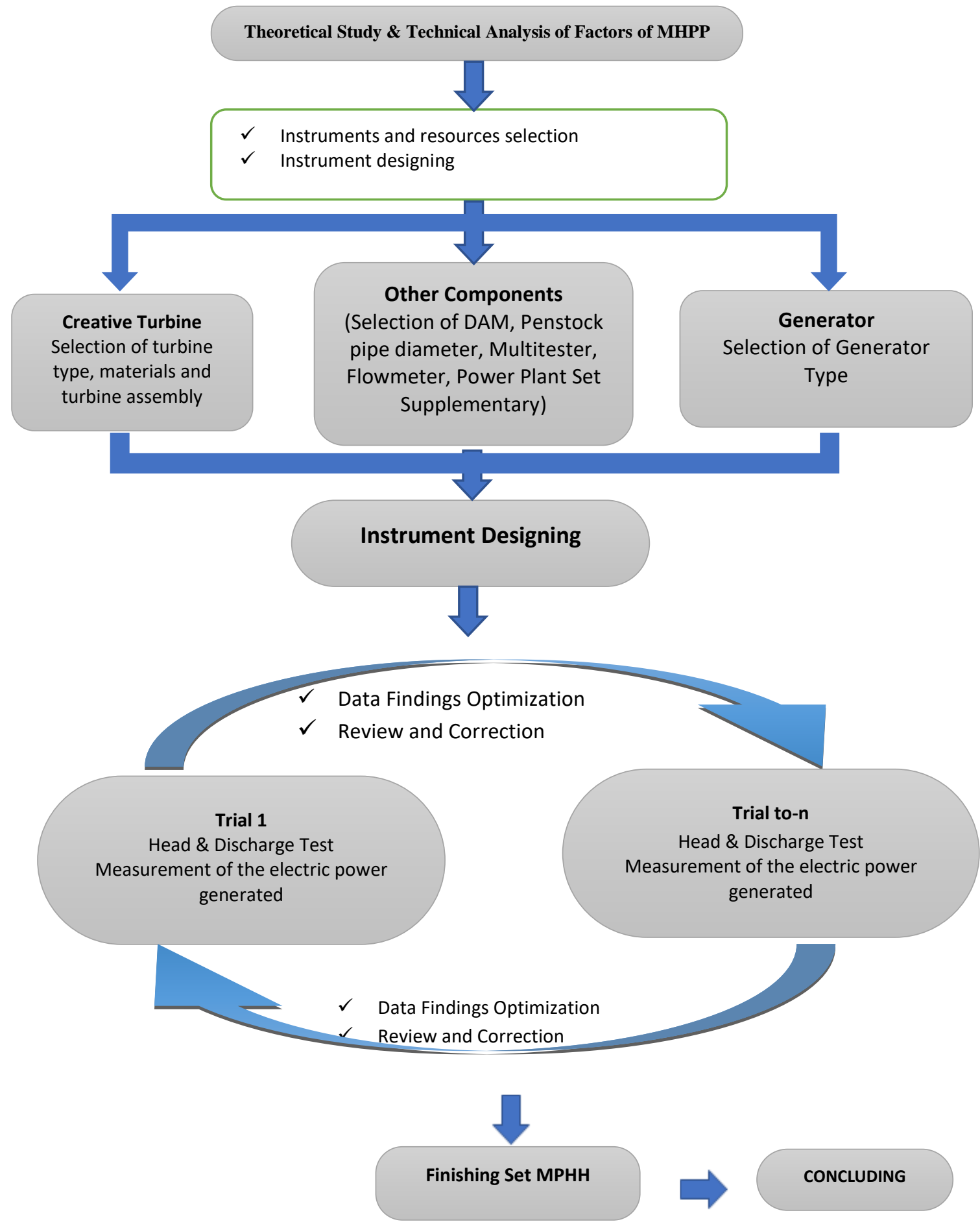

Figure 9. Research Phase 


\section{Results and Discussion}

The following data and studies have been obtained from the development of the Micro Hydro Power Plant (MHPP) as a learning platform for basic physics practice.

The Calculation of The Potential for Electric Power $P_{\text {theoretical }}$ from Water Discharge $Q$

Water discharge is used to identify the potential for theoretical electricity generation (Marliansyah et al., 2018; Nasir, 2014). In this case the theoretical electrical power is assumed to be the input power $P_{\text {in }}$. The measured discharge (Q) of water and the amount of electrical power generated by $P_{\text {theoretical }}$ with a head of $10 \mathrm{~cm}$ are shown in Table 2.

Table 2. Water Discharge $(\mathrm{Q})$ as A Power Input $\left(\mathrm{P}_{\mathrm{in}}\right)$

\begin{tabular}{ccc}
\hline No. & Water Discharge Q $(\mathrm{g} / \mathrm{s})$ & Power $P_{\mathrm{In}}=$ o.Q.g.h $(\mathrm{mW})$ \\
\hline 1. & 32.9 & 32.9 \\
2. & 35.6 & 35.6 \\
3. & 33.1 & 33.1 \\
4. & 38.4 & 38.4 \\
5. & 38.2 & 38.2 \\
\hline Average & 35.64 & 35.64 \\
\hline Efficiency $\eta$ (min-max) teroritik (10-80 \%) & & $(3.56-28.51)$ \\
\hline
\end{tabular}

The theoretical power $\left(\mathrm{P}_{\text {in }}\right)$ is proportional to the height $(\mathrm{h})$ and discharge (Q) (Safdar et al., 2020). This is in accordance with the equation that was discussed in the previous chapter, specifically $\mathrm{P}_{\text {theoretical }}=\rho Q g h$ (Michael \& Jawahar, 2017). The amount of theoretical power $\mathrm{P}_{\text {in }}$ generated No.1 in Table 2. was obtained with the Formula 5.

$$
\begin{aligned}
P_{\text {in }} & =\rho \cdot Q \cdot g \cdot h \\
& =1000 \frac{\mathrm{kg}}{\mathrm{m}^{3}} \cdot 32,910^{-6} \frac{\mathrm{m}^{3}}{\mathrm{~s}} \cdot 10 \frac{\mathrm{m}}{\mathrm{s}^{2}} \cdot 10^{-2} \mathrm{~m} \\
& =32,910^{-3} \mathrm{~kg} \frac{\mathrm{m}^{2}}{\mathrm{~s}^{3}} \\
& =32,9 \mathrm{~mW}
\end{aligned}
$$

By using identical calculation, the $P_{\text {in }}$ input power obtained for number 2 to 5 was 35.6 , and so on, up to $38.2 \mathrm{~mW}$. The average theoretical electric power generated from the water discharge was $35.64 \mathrm{~mW}$.

The efficiency of the instrument system was determined in the range of 10 to 80 percent. In this study, the authors determined a maximum limit of 80 percent because it is impossible for a device to generate 100 percent output power. Also, the minimum output power limit was set at 10 percent, instead of zero, because if the output was zero or too low, it means that the mini MHPP instrument set is not working properly or even damaged.

To calculate the efficiency, it used $\eta=\frac{P_{\text {out }}}{P_{\text {input }}} \times 100 \%$. The minimum allowable efficiency was set at 10 percent, as then the minimum input power generated was as follows.

$$
\begin{gathered}
\eta_{\text {minteoritik }}=\frac{P_{\min }}{P_{\text {in }}} \times 100 \% \\
10 \%=\frac{P_{\min }}{35.64 \mathrm{~mW}} \times 100 \% \\
P_{\min }=3,56 \mathrm{~mW}
\end{gathered}
$$

Therefore, the theoretical minimum power limit $P_{\min }$ obtained was $3.56 \mathrm{~mW}$. In the same way, a maximum power limit of 80 percent was obtained, which was $28.51 \mathrm{~mW}$. From the results of the discharge, it can be estimated that the output power would be in the range of minimum and maximum values, in specific (3.56 - 28.51) mWatt. 
Real power measurement $\left(\mathrm{P}_{\text {real }}\right)$ generated from MPHH

The amount of electric power $P_{\text {real }}$ was obtained indirectly from the measurement of the current $\mathrm{I}$ and the voltage $\mathrm{V}$ installed in the mini MHP generator.

Table 3. Current I, Voltage, and Output Electrical Power $\left(\mathrm{P}_{\text {real }}\right)$

\begin{tabular}{cccc}
\hline No. & Current I $(\mathrm{mA})$ & Voltage $(\mathrm{V})$ & Output $\mathbf{P}_{\text {real }}(\mathrm{mW})$ \\
\hline 1. & 6.74 & 1.2 & 8.09 \\
2. & 8.38 & 1.2 & 10.06 \\
3. & 7.45 & 1.2 & 8.98 \\
4. & 8.26 & 1.3 & 10.74 \\
5. & 7.86 & 1.3 & 10.22 \\
& & & 9.61 \\
\hline
\end{tabular}

The resulting output power $\mathrm{P}_{\text {real }}$ was calculated by the equation of $P_{\text {real }}=V I$. In this study, the average output power $\mathrm{P}_{\text {real }}$ produced by this mini MHPP was $9.61 \mathrm{~mW}$. If the theoretical power value generated by the discharge of water that comes out was compared, the amount of output power $\left(\mathrm{P}_{\text {real }}=9.61 \mathrm{~mW}\right)$ was still within the theoretical minimum and maximum power thresholds, $\left(P_{\text {minteoritik }}-P_{\text {maxteoritik }}\right)=(3.56-28.51) \mathrm{mW}$.

Comparison of electric power and efficiency as well as analysis of factors that affect mini MHP plants

By using the calculation formula $\eta=\frac{P_{\text {out }}}{P_{\text {input }}} \times 100 \%=\frac{V \cdot I}{\rho \cdot Q \cdot g \cdot h}$, it obtained an efficiency of MHPP of 26.96 percent (Bortoni et al., 2015; Kumar \& Singal, 2015; Pasalli \& Rehiara, 2014). The explanation of calculation is presented by Formula 7.

$\eta_{\text {alat }}=\frac{P_{\text {real }}}{P_{\text {teoritik }}} \times 100 \%=\frac{9.61 \mathrm{~mW}}{35.64 \mathrm{~mW}} \times 100 \%=26.96 \%$

The amount of electric power $\mathrm{P}$ and the resulting efficiency between the theoretical values and this instrument are presented in Table 4. The comparison of the amount of theoretical electric power and the instrument can be seen in Figure 10. While the comparison of the efficiency of the instrument with the theoretical minimum and maximum efficiency can be seen in Figure 11.

Table 4. Electrical Power P and Instrument Efficiency $\eta$

\begin{tabular}{lccc}
\hline & Minimum Theoretical & Instrument & Maximum Theoretical \\
\hline Electrical Power P $(\mathrm{mW})$ & 3.56 & 9.61 & 28.51 \\
Efficiency $\eta(\%)$ & 10 & 26.6 & 80
\end{tabular}

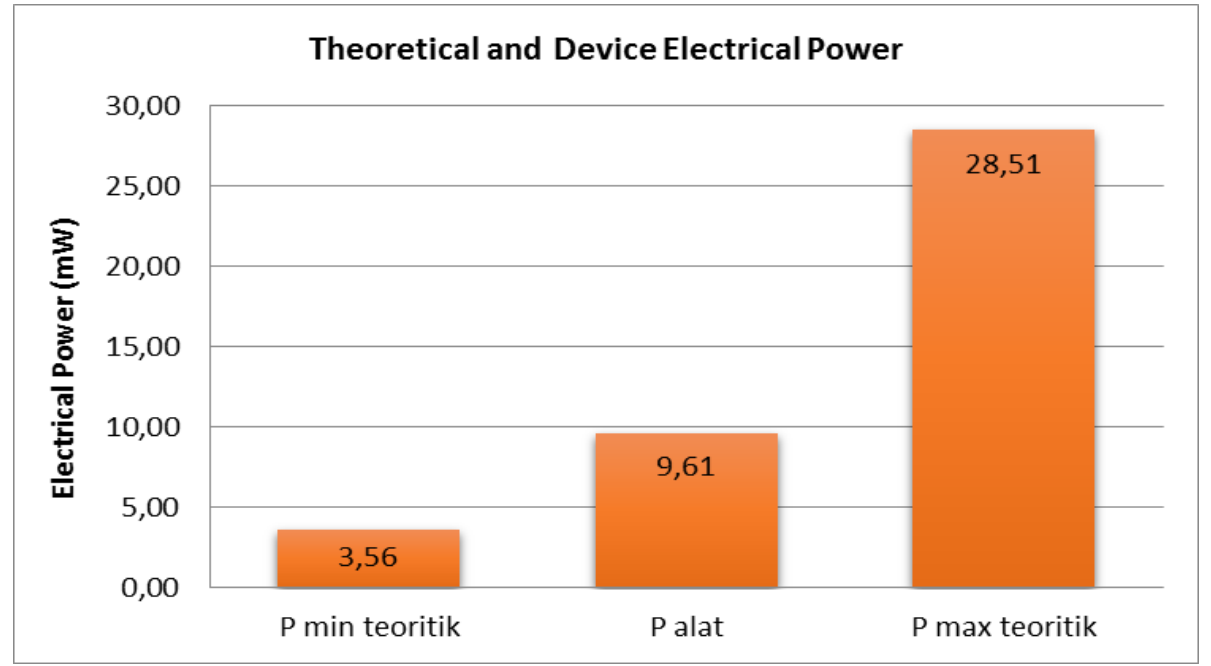

Figure 10. Correlation between instrument and theoretical electric power of MHPP 
The theoretical minimum potential electric power generated from the water discharge calculation was $3.56 \mathrm{~mW}$, while the maximum power was $28.51 \mathrm{~mW}$. In the instrument that was successfully made, the electrical power generated was $9.61 \mathrm{~mW}$. This is still in accordance with the large potential of electric power, which is still within the range of the potential for electric power generated.

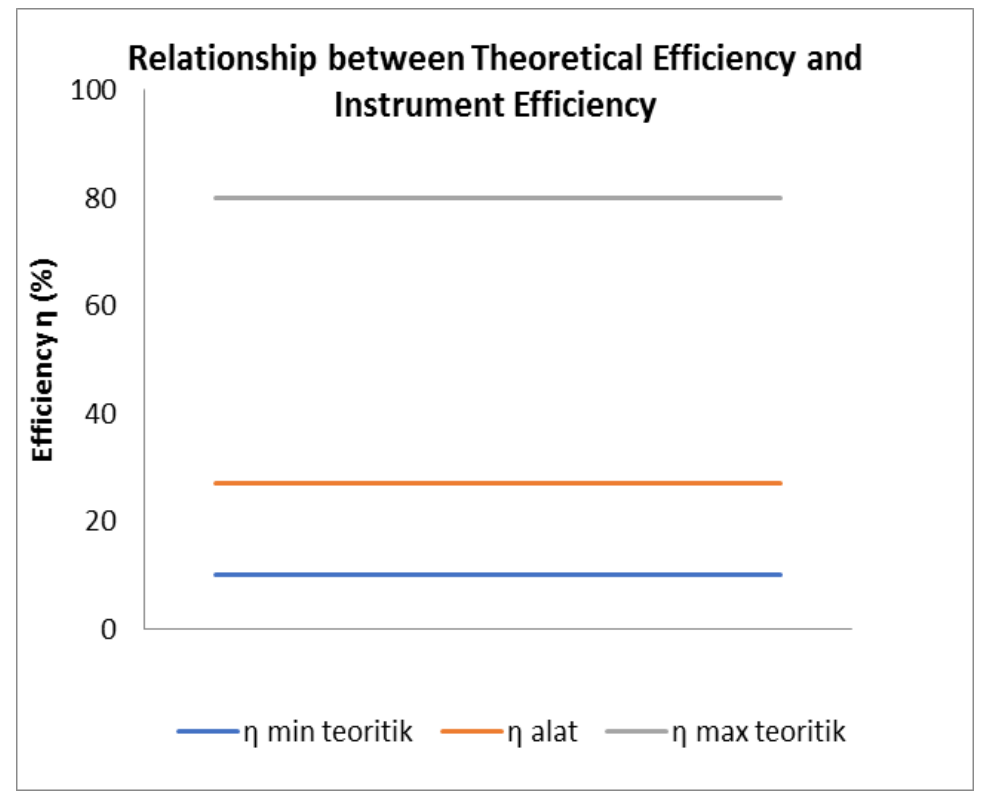

Figure 11. Correlation between instrument and theoretical efficiency of MHPP

The efficiency value generated by this Mini MHP generator is not relatively substantial, but still within the range of the minimum and maximum efficiencies allowed (Figure 11) (Kumano et al., 2018). Numerous factors influence the whole sub-optimal efficiency, among other things, in terms of turbines, penstock pipes, generators, as well as changes in other energy (Ciric, 2019; Hatata et al., 2019).

In terms of the structure of the turbine, numerous aspects that need to be considered, including the diameter of the nozzle, the number of blades, the angle of inlet jet, the volume and the speed of the blade, need to be adjusted (Laghari et al., 2013). The choice of the form of the turbine must be very appropriate, which include the volume of the turbine blade with the amount of water, the shape of the blade must also be adjusted to the angle of the incoming water, the height of the reservoir and the type of water flow (Jawahar \& Michael, 2017; Signe et al., 2017). The speed and angle of the jet propulsion of the bucket must also be considered (Nazari-Heris \& MohammadiIvatloo, 2017). In addition, the tail-race outflow of water is also considered in such a way that it does not interfere with the rotation, because a bad tail-race outflow that exceeds the capacity may hinder the rotation of the turbine due to disturbance of the water that cannot emerge properly. This affects indirectly the shape and size of the turbine housing.

As for the dam and the reservoir, it should be made with a large volume of wide dimensions, instead of rising dimension. This is done in such a way that the water pressure from the penstock pipe is not significantly affected by the reduction in the height of the reservoir dam. Reducing the height of the reservoir can reduce water discharge dramatically. As far as the penstock pipe is concerned, the water pressure level in the penstock pipe and the amount of water flowing in the penstock pipe must be properly controlled hence the maximum efficiency results (Nazari-Heris \& Mohammadi-Ivatloo, 2017). There is also a change in the potential energy and kinetic energy of the water in this place. As far as generators are concerned, the specifications and types of generators and their power capacity must be adjusted to the water discharge hence the generator can generate maximum efficiency (Cavazzini et al., 2018; Hatata et al., 2019). The connection between the turbine shaft and the generator, the gear wheel and the belt, which are not properly installed, makes the turbine-generator rotation less efficient. In addition, the less than optimal efficiency of this mini 
MHPP generator can be caused by the friction force of the turbine generator shaft, as well as by the turbine generator shaft and belt, which produces sound and heat energy (Saket, 2013). Because essentially, the developed MHPP cannot convert mechanical energy into electrical energy as a whole, but there is other energy produced, such as heat and sound. Mechanical energy consisting of potential energy in the form of falling water and kinetic energy in the form of a flow of water falling into the turbine (Signe et al., 2017).

\section{Conclusion}

The conclusion that can be drawn from this research is the amount of input power $P_{\text {in }}$ from the set of MHPP practicum instruments resulting from the measurement of water discharge was $35.64 \mathrm{~mW}$. The output power output of $P_{\text {out }}$ from the PLTMH practical instrument set was $9.61 \mathrm{~mW}$. While the efficiency obtained was 26.96 percent. The efficiency value that was not substantial due to several factors, including turbine blades, penstock pipes, in terms of generators, and other unavoidable changes to energy.

\section{References}

Bhatia, S. C. (2014). Hydroelectric power. In Advanced Renewable Energy Systems (pp. 240-269). Elsevier. https://doi.org/10.1016/B978-1-78242-269-3.50010-3

Bortoni, E. C., Bastos, G. S., Abreu, T. M., \& Kawkabani, B. (2015). Online optimal power distribution between units of a hydro power plant. Renewable Energy, 75, 30-36. https://doi.org/10.1016/j.renene.2014.09.009

Cavazzini, G., Houdeline, J.-B., Pavesi, G., Teller, O., \& Ardizzon, G. (2018). Unstable behaviour of pump-turbines and its effects on power regulation capacity of pumped-hydro energy storage plants. Renewable and Sustainable Energy Reviews, 94(April 2017), 399-409. https://doi.org/10.1016/j.rser.2018.06.018

Ciric, R. M. (2019). Review of techno-economic and environmental aspects of building small hydro electric plants - A case study in Serbia. Renewable Energy, 140, 715-721. https://doi.org/10.1016/j.renene.2019.03.091

Erinofiardi, Nuramal, A., Bismantolo, P., Date, A., Akbarzadeh, A., Mainil, A. K., \& Suryono, A. F. (2017). Experimental study of screw turbine performance based on different angle of inclination. Energy Procedia, 110, 8-13. https://doi.org/10.1016/j.egypro.2017.03.094

Goyena, R. (2019). Statistik ketenagalistrikan (electricity statistics). Journal of Chemical Information and Modeling, 53(9), 1689-1699.

Hatata, A. Y., El-Saadawi, M. M., \& Saad, S. (2019). A feasibility study of small hydro power for selected locations in Egypt. Energy Strategy Reviews, 24(April 2018), 300-313. https://doi.org/10.1016/j.esr.2019.04.013

Jawahar, C. P., \& Michael, P. A. (2017). A review on turbines for micro hydro power plant. Renewable and Sustainable Energy Reviews, 72(January), 882-887. https://doi.org/10.1016/j.rser.2017.01.133

Kumano, T., Matsunawa, K., \& Nishiyama, R. (2018). Experimental test and feasibility study of a micro in-pipe hydro power generator at a university building. IFAC-PapersOnLine, 51(28), 380-385. https://doi.org/10.1016/j.ifacol.2018.11.732

Kumar, R., \& Singal, S. K. (2015). Operation and maintenance problems in hydro turbine material in small hydro power plant. Materials Today: Proceedings, 2(4-5), 2323-2331. https://doi.org/10.1016/j.matpr.2015.07.284

Laghari, J. A., Mokhlis, H., Bakar, A. H. A., \& Mohammad, H. (2013). A comprehensive overview of new designs in the hydraulic, electrical equipments and controllers of mini hydro power plants making it cost effective technology. Renewable and Sustainable Energy Reviews, 20, 279-293. 
https://doi.org/10.1016/j.rser.2012.12.002

Lahimer, A. A., Alghoul, M. A., Sopian, K., Amin, N., Asim, N., \& Fadhel, M. I. (2012). Research and development aspects of pico-hydro power. Renewable and Sustainable Energy Reviews, 16(8), 5861-5878. https://doi.org/10.1016/j.rser.2012.05.001

Marliansyah, R., Putri, D. N., Khootama, A., \& Hermansyah, H. (2018). Optimization potential analysis of micro-hydro power plant (MHPP) from river with low head. Energy Procedia, 153, 74-79. https://doi.org/10.1016/j.egypro.2018.10.021

Michael, P. A., \& Jawahar, C. P. (2017). Design of $15 \mathrm{~kW}$ micro hydro power plant for rural electrification at Valara. Energy Procedia, 117, 163-171. https://doi.org/10.1016/j.egypro.2017.05.119

Nasir, B. A. (2014). Design considerations of micro-hydro-electric power plant. Energy Procedia, 50, 19-29. https://doi.org/10.1016/j.egypro.2014.06.003

Nazari-Heris, M., \& Mohammadi-Ivatloo, B. (2017). Design of small hydro generation systems. In Distributed Generation Systems (pp. 301-332). Elsevier. https://doi.org/10.1016/B978-0-12804208-3.00006-6

Pasalli, Y. R., \& Rehiara, A. B. (2014). Design planning of micro-hydro power plant in hink river. Procedia Environmental Sciences, 20, 55-63. https://doi.org/10.1016/j.proenv.2014.03.009

Safdar, I., Sultan, S., Raza, H. A., Umer, M., \& Ali, M. (2020). Empirical analysis of turbine and generator efficiency of a pico hydro system. Sustainable Energy Technologies and Assessments, 37(November 2019), 1-7. https://doi.org/10.1016/j.seta.2019.100605

Saket, R. K. (2013). Design aspects and probabilistic approach for generation reliability evaluation of MWW based micro-hydro power plant. Renewable and Sustainable Energy Reviews, 28, 917929. https://doi.org/10.1016/j.rser.2013.08.033

Signe, E. B. K., Bogno, B., Aillerie, M., \& Hamandjoda, O. (2019). Performance in feasibility studies of micro hydro power plants. New software development and application cases in Cameroon. Energy Procedia, 157, 1391-1403. https://doi.org/10.1016/j.egypro.2018.11.304

Signe, E. B. K., Hamandjoda, O., \& Nganhou, J. (2017). Methodology of feasibility studies of microhydro power plants in Cameroon: Case of the micro-hydro of KEMKEN. Energy Procedia, 119, 17-28. https://doi.org/10.1016/j.egypro.2017.07.042

Sungai, A., Di, O. O. T., Peneliti, T., Suarda, I. M., Eng, M., Ngakan, D., Putra, K., Astawa, I. K., Putu, S., Gunawan, G., Dipa, D., Udayana, U., Teknik, F., \& Udayana, U. (2008). Laporan penelitian. 1-37.

Syahrial, E., Adam, R., Suharyati, Ajiwihanti, N., Indarwati, R. R. F., Kurniawan, F., Kurniawan, A., \& Suzanti, V. M. (2011). Handbook of Energy \& Economic Statistics of Indonesia.

Tapia, A., Millán, P., \& Gómez-Estern, F. (2018). Integer programming to optimize Micro-Hydro Power Plants for generic river profiles. Renewable Energy, 126, 905-914.

https://doi.org/10.1016/j.renene.2018.04.003

Triboesono, A. (2018). Statistik ketenagalistrikan. Direktorat Jenderal Ketenagalistrikan Kementrian Energi dan Sumber Daya Mineral. 